\title{
Analisis Penerapan Activity Based Costing System Dalam Menentukan Harga Pokok Kamar Pada The Belagri Hotel and Convention Sorong
}

\author{
Oleh: Jemmy Poandy,SE \\ Jurusan Akuntansi Keuangan Publik \\ Program Studi Sarjana Terapan Akuntansi Keuangan Publik \\ Politeknik Katolik Saint Paul Sorong \\ Email: jpoandy@yahoo.co.id
}

\begin{abstract}
ABSTRAK
The Belagri Hotel and Convention Sorong merupakan perusahaan jasa yang bergerak dibidang penyediaan jasa penginapan, makan dan minum serta fasilitas lain. Perusahaan menerapkan sistem Activity Based Costing adalah metode penentuan harga yang menelusur biaya ke aktivitas, kemudian ke produk. Metode Activity Based Costing dinilai lebih akurat dalam membebankan biaya overhead kepada produk karena menggunakan lebih dari satu cost driver. Sehingga biaya overhead yang dialokasikan akan lebih proporsional. Tetapi dalam penerapan Activity Based Costing System (ABC) pada perusahaan ada beberapa biaya yang dapat menimbulkan aktivitas tidak dimasukkan dalam penentuan harga pokok produksi kamar. Hasil penelitian menunjukkan terdapat selisih harga yang lebih tinggi dari penetapan harga manajemen hotel dengan hasil perhitungan yaitu, untuk kamar Superior sebesar Rp 7.894, untuk kamar Deluxe sebesar Rp 10.373, untuk kamar Premier sebesar Rp 12.676, untuk kamar Junior Suite sebesar Rp 32.839, untuk kamar Executive Suite sebesar Rp 53.720, dan untuk kamar President Suite sebesar Rp 406.069.
\end{abstract}

Kata Kunci: Activity Based Costing, Harga Pokok Produksi

\section{ABSTRACT}

The Belagri Hotel and Convention Sorong is a service company specializing in the provision of accommodation services, food and drink as well as other amenities. The company implements the system of Activity Based Costing is a pricing method that searches for activity costs, then to the product. Activity Based Costing method is considered more accurate in overhead charge to the product because it uses more than one cost driver. So the overhead allocated will be proportional. But in the application of Activity Based Costing System (ABC) to the company there are some costs that can lead to activities not included in determining the cost of production rooms. The results showed a difference in price is higher than the pricing of hotel management by the calculation that, for a Superior room $R p$ 7.894, for a Deluxe room Rp 10.373, to room Premier $R p$ 12.676, to the Junior Suite $R p$ 32.840, room Executive Suite $R p 53.720$ and room Presidential Suite $R p 406.069$.

Keywords: Activity Based Costing, Cost of Production

\section{Pendahuluan}

\subsection{Latar Belakang}

Industri pariwisata merupakan jenis industri yang mempunyai mata rantai kegiatan yang sangat panjang. Berkembangnya industri pariwisata disuatu daerah akan menarik sektor lain untuk berkembang karena produknya atau jasanya diperlukan untuk menunjang industri pariwisata, seperti sektor pertanian, perternakan, dan perkebunan.Pertumbuhan industri pariwisata salah satunya dapat dilihat dari industri jasa penginapan yang juga dipengaruhi oleh perkembangan hotel yang dikelola baik pengelola dalam negeri maupun luar negeri. Bertambahnya hotel akan menyebabkan persaingan bisnis yang sejenis. Kondisi ini menuntut para pelaku usaha untuk fokus, menjamin kualitas dan pelayanan, serta harga yang terjangkau. Perusahaan harus dapat secara efisien dan efektif menentukan harga yang sesuai dengan kualitas dan pelayanan yang diberikan agar mampu bertahan melawan pesaing. Penetapan biaya yang tepat akan menghasilkan biaya yang akurat, efisien, dan efektif. Penetapan biaya juga berpengaruh pada penentuan harga pokok. harga pokok poduksi adalah biaya-biaya yang dikeluarkan mulai 
pada pengadaaan bahan baku tersebut sampai dengan proses akhir produk, yang siap untuk digunakan atau dijual. Dalam penentuan harga pokok kamar, The Belagri Hotel and Convention Sorong menggunakan metode Activity Based Costing System (ABC System) yang dimana metode Activity Based Costing System merupakan sistem yang menerapkan konsep-konsep aktivitas untuk menghasilkan perhitungan harga pokok yang lebih akurat. Perhitungan biaya berdasarkan aktivitas merupakan pendekatan perhitungan biaya yang membebankan biaya sumber daya ke objek biaya seperti produk, jasa, atau pelanggan berdasarkan aktivitas yang dilakukan untuk objek biaya tersebut.

Metode ABC merupakan solusi

alternatif yang dapat diterapkan dalam hotel karena pendekatan metode ini menggunakan pemicu biaya berdasarkan aktivitas yang menimbulkan biaya. Metode ini akan berfungsi lebih optimal, efektif, dan efisien apabila diterapkan pada perusahaan yang menghasilkan produk beraneka ragam. Tetapi ada beberapa aktivitas yang dapat menimbulkan biaya tetapi tidak di masukkan dalam penentuan harga pokok hal ini dapat mempengaruhi harga pokok produksi pada hotel, Berdasarkan uraian diatas maka penulis tertarik untuk mengambil judul "Analisis Penerapan Activity Based Costing System Dalam Menentukan Harga Pokok Kamar Pada The Belagri Hotel and Convention Sorong".

\section{Tinjauan Pustaka}

\subsection{Definisi Biaya}

Dalam melaksanakan tanggung jawab perencanaan dan pengendalian manajemen membutuhkan pemahaman akan arti biaya dan terminologi yang berkaitan dengan biaya. Pembebanan biaya atas produk, jasa, pelanggan dan objek lain yang merupakan kepentingan manajemen, adalah salah satu tujuan dasar sistem informasi akuntasi manajemen. Sebelum membicarakan proses penentuan biaya, baiknya menentukan mengenai definisi biaya (cost). Cecily A.Raiborn dan Michael (2011) mendefinisikan biaya sebagai berikut Biaya adalah uang kertas atau nilai setara kas yang diperlukan untuk mencapai suatu tujuan seperti memperoleh barang dan jasa, sesuai dengan kontrak, melakukan fungsi, atau memproduksi dan mendistribusikan produk.

\subsubsection{Penggolongan Biaya}

Berikut ini penggolongan biaya menurut Mulyadi (2014) Dalam akuntansi biaya, biaya digolongkan dengan berbagai macam cara. Umumnya penggolongan biaya ini ditentukan atas dasar tujuan yang hendak dicapai dengan penggolongan tersebut, karena dalam akuntansi biaya dikenal konsep. "different costs for different purposes". Biaya dapat digolongkan menurut:

1. Objek Pengeluaran

2. fungsi pokok dalam perusahaan

3. hubungan biaya dengan sesuatu yang dibiayai

4. perilaku biaya dalam hubungannya dengan perubahan volume kegiatan

5. jangka waktu manfaatnya.

\subsection{Harga Pokok Produksi}

Harga pokok adalah istilah yang digunakan pada akuntansi keuangan untuk menggambarkan biaya langsung yang timbul dari barang yang diproduksi dan dijual dalam kegiatan bisnis. Harga pokok produk merupakan salah satu hal penting yang perlu diperhatikan oleh perusahaan baik perusahaan manufaktur, perusahaan jasa maupun perusahaan dagang. Menurut Al Haryono Jusup (2011) harga pokok produk merupakan semua pengeluaran yang diperlukan untuk mendapatkan barang dan menempatkannya dalam kondisi yang siap untuk di jual

\subsection{Hotel}

Menurut Grolier Electronic Publishing Inc. (1995) mengemukakan bahwa hotel adalah usaha komersial yang menyediakan tempat menginap, makanan, dan pelayanan-pelayanan lain untuk umum.

\subsection{Activity Based Costing System (ABC System)}

\subsubsection{Pengertian Activity Based Costing System (ABC System)}

Activity Based Costing system (ABC) merupakan sistem yang menerapkan konsepkonsep aktivitas untuk menghasilkan perhitungan harga pokok yang lebih akurat. Menurut Mulyadi (2007) Activity Based Costing System (ABC) adalah sistem informasi biaya yang berorientasi pada penyediaan 
informasi lengkap tentang aktivitas untuk memungkinkan personel perusahaan.

\subsubsection{Manfaat Activity Based Costing System (ABC System)}

ABC System adalah sistem informasi biaya yang bermanfaat untuk memantau implementasi rencana. Sistem ini merupakan alat manjemen kontemporer yang didesain untuk diterapkan dalam berbagai jenis perusahaan: manufaktur jasa, dan dagang.

\subsubsection{Tahap-Tahap Pengolahan Data Dalam Activity Based Costing System (ABC System)}

A. Tahap pertama : pembebanan sumber daya ke aktivitas Pengolahan data dalam ABC System disebut activity based process costing.

B. Tahap kedua: pembebanan activity cost ke produk/jasa

Proses pengolahan data dalam ABC System disebut activity based object costing. Pada tahap kedua ini berisi tiga kegiatan yaitu:

1. Penentuan activity cost pool

2. Pembebanan biaya antar aktivitas

\subsubsection{Aktivitas Pemicu Biaya (Cost Driver)}

Suatu pemicu biaya harus mudah dimengerti, berhubungan langsung kepada aktivitas yang dijalankan dan sesuai dengan pengukuran prestasi. Manajemen harus membatasi pemicu biaya yang terpilih untuk menentukan bahwa biaya pengukuran pemicu tersebut tidak melebihi manfaat penggunaannya.

\subsubsection{Keterbatasan Activity Based Costing System (ABC System)}

Terdapat tiga keterbatasan dalam penerapan Sistem ABC Blocher dkk (2007), yaitu :

\section{Alokasi}

Tidak semua biaya memiliki penggerak biaya konsumsi sumber daya atau aktivitas yang tepat atau tidak ganda.

2. Mengabaikan biaya.

Biaya produk atau jasa yang diidentifikasi sistem $\mathrm{ABC}$ cenderung tidak mencakup seluruh biaya yang berhubungan dengan produk atau jasa tersebut.

3. Mahal dan menghabiskan waktu.
Sistem ABC tidak murah dan membutuhkan banyak waktu untuk dikembangkan dan dilaksanakan.

\subsubsection{Penerapan Activity Based Costing System (ABC System) Pada Perusahaan Jasa}

Sistem $A B C$ pada mulanya berkembang pada perusahaan manufaktur yang memiliki teknologi tinggi, yang artinya biaya peralatan jauh lebih besar dibandingkan dengan biaya tenaga kerja, karena mekanisme proses produksi dapat dinyatakan secara otomatis (terkomputerisasi). Menurut Blocher dkk (2007) Output dalam perusahaan jasa lebih sulit didefinisikan, aktivitas untuk memenuhi permintaan jasa juga lebih sulit diprediksi, dan biaya overhead atau biaya tak langsung sulit untuk dibandingkan ke produk atau output.

\section{Metodologi Penelitian}

\subsection{Objek Penelitian}

Pada penelitian ini, yang menjadi objek penelitian adalah penerapan metode Activity Based Costing System dalam penentuan harga pokok kamar The Belagri Hotel and Convention.

\subsection{Tempat dan Waktu Penelitian}

Pada Penelitian ini penulis melakukan penelitian di The Belagri and Conve ntion sorong yang berlokasi di Jalan G. Merapi No. 8 Sorong. Waktu penelitian dimulai dari awal Mei 2016 sampai dengan selesai.

\subsection{Metode Pengumpulan Data}

Metode pengumpulan data yang digunakan dalam penelitian ini adalah:

a. Penelitian Kepustakaan

b. Penelitian Lapangan, yaitu penelitian yang dilakukan dengan teknik:

1. Observasi, yaitu teknik penelitian yang dilakukan dengan mengadakan pengamatan secara langsung dalam perusahaan.

2. Wawancara, yaitu teknik penelitian yang dilakukan dengan mengadakan wawancara atau tanya-jawab dengan pihak perusahaan yang ditunjuk atau pejabat berwenang yang ada hubungannya dengan data-data proses 
produksi dan biaya produksi yang dibahas dalam penelitian ini.

\subsection{Jenis dan Sumber Data}

Adapun jenis data yang digunakan dalam penulisan ini adalah :

1) Data Kualitatif, yaitu data yang diperoleh dari dalam perusahaan yang bukan dalam bentuk angka-angka tetapi dalam bentuk lisan maupun tertulis seperti gambaran umum perusahaan, prosedur-prosedur perusahaan, dan pembagian tugas masingmasing departemen dalam perusahaan.

2) Data Kuantitatif, yaitu data atau informasi yang diperoleh dari perusahaan dalam bentuk angka-angka, seperti laporan jumlah pelanggan, laporan biaya-biaya yang terkait, dan lain-lain.

Sedangkan sumber data yang digunakan penulis dalam penulisan skripsi ini adalah :

a) Data primer, yaitu data yang diperoleh dengan mengadakan pengamatan secara langsung pada perusahaan serta melakukan wawancara langsung dengan pihak pimpinan dan sejumlah personil yang ada kaitannya dengan penelitian ini.

b) Data sekunder, yaitu data yang diperoleh dengan jalan mengumpulkan dokumendokumen serta arsip-arsip perusahaan yang ada kaitannya dengan penulisan ini.

\subsection{Metode Analisis}

Metode analisis yang digunakan pada penelitian ini adalah metode analisis deskriptif kuantitatif yaitu analisis yang berdasarkan keputusan pada penilaian obyektif yang didasarkan pada model matematika yang dibuat.

Langkah-langkah analisis dalam penelitian ini antara lain :

1. Mencantumkan harga pokok produksi kamar The Belagri Hotel and Convention Sorong dengan menggunakan metode $\mathrm{ABC}$ system yang telah digunakan oleh The Belagri Hotel and Convention Sorong.

2. Mengidentifikasi aktivitas-aktivitas dan menghubungkan aktivitas-aktivitasnya.

3. Biaya inderect cost diidentifikasi dulu biaya aktivitasnya

4. Kemudian menghubungkan cost driver dengan tiap aktivitasnya

5. Membebankan biaya overhead.
6. Membandingkan antara perhitungan harga pokok produksi kamar hotel dengan perhitungan Harga Pokok Produksi kamar hasil analisis.

\section{Hasil dan Pembahasan}

\subsection{Data Pendukung ABC System}

Data Pendukung Activity Based Costing System Dalam menentukan Harga Pokok Produksi dengan metode Activity Based Costing, data-data yang dibutuhkan antar lain jumlah kamar terjual, jumlah tamu menginap, luas ruangan dan jumlah kamar tiap jenis kamar. Langkah-langkah dalam menghitung harga pokok produksi kamar dengan metode Activity Based Costing System yang digunakan oleh The Belagri Hotel and Convention:

\subsection{Perhitungan Harga Pokok Produksi Kamar Dengan Menggunakan Activity Based Costing System}

\subsubsection{Mengidentifikasi Biaya dan Aktivitas yang Terjadi}

Mengidentifikasi biaya-biaya yang termasuk dalam biaya langsung atau direct cost dan biaya tidak langsung atau indirect cost. Kemudian biaya-biaya yang termasuk dalam biaya langsung dialokasikan ke tiap jenis kamar mulai dari superior, deluxe, premier, junior suite, executive suite dan president suite. 


\subsubsection{Mengidentifikasi Aktivitas Biaya Tidak Langsung dan Level Aktivitasnya}

Tabel 4.5

Identifikasi Aktivitas dan Level Aktivitas

\begin{tabular}{|c|l|l|}
\hline No & \multicolumn{1}{|c|}{ Aktivitas } & Level aktivitas \\
\hline 1 & Aktivitas penginapan tamu & Unit level \\
\hline 2 & Aktivitas laundry & Unit level \\
\hline 3 & Aktivitas pemberian makan pagi & Unit level \\
\hline 4 & Aktivitas listrik & Facility level \\
\hline 6 & Aktivitas air & Facility level \\
\hline 7 & Aktivitas penyusutan & Facility level \\
\hline 8 & Aktivitas penggajian & Facility level \\
\hline
\end{tabular}

Sumber: The Belagri Hotel and Convention Sorong, 2015

\subsubsection{Mengidentifikasi Cost Driver}

Tabel 4.6

Cost Pool Dan Cost Driver

\begin{tabular}{|l|l|}
\hline Cost Pool & Cost driver \\
\hline Unit level Activity: & \\
Poo 1 I & Jumlah kamar terjual \\
Aktivitas Penginapan & Jumlah kamar terjual \\
Aktivitas laundry & Jumlah kamar terjual \\
Aktivitas listrik & Jumlah kamar terjual \\
Aktivitas air & \\
Pool II & Jumlah tamu menginap \\
Aktivitas pemberian makan pagi & \\
Facility Level Activity & \\
\hline Pool I & Jumlah luas ruangan \\
Aktiivitas penyusutan & \\
Pool IV & Jumlah jam kerja \\
\hline
\end{tabular}

Sumber: The Belagri Hotel and Convention, 2015

\subsubsection{Membebankan Biaya Overhead}

Tabel 4.7

Cost Pool I

\begin{tabular}{|c|c|}
\hline Aktivitas & Biaya (Rp) \\
\hline Aktivitas penginapan: & \\
\hline Guest supplies & $\mathrm{Rp} 4.629 .860 .000$ \\
\hline Room amenities & $\mathrm{Rp} 1.518 .400 .000$ \\
\hline Cleaning supplies & $\mathrm{Rp} \quad 29.380 .000$ \\
\hline Aktivitas laundry: & \\
\hline laundry linen & $\mathrm{Rp} 72.617 .110,00$ \\
\hline Aktivitas listrik: & \\
\hline Listrik(Rp960,000,000 x 65\%) & 624.000 .000 \\
\hline Aktivitas air : & \\
\hline Air $(\mathrm{Rp} 108,000,000 \times 65 \%)$ & $\mathrm{Rp} \quad 70.200 .000$ \\
\hline Total & $\mathrm{Rp} 6.944 .457 .110$ \\
\hline
\end{tabular}

Sumber: The Belagri Hotel and Convention, 2015 
Tabel 4.8

Cost Pool II

\begin{tabular}{|l|lr|}
\hline Aktivitas & Biaya $(\mathrm{Rp})$ \\
\hline Aktivitas makan pagi & \multicolumn{2}{|l|}{} \\
Makan pagi (Rp50.000 x 4495 orang) & $\mathrm{Rp}$ & $224,750,000$ \\
\hline Total & $\mathrm{Rp}$ & $224,750,000$ \\
\hline
\end{tabular}

Sumber: The Belagri Hotel and Convention, 2015

Tabel 4.9

Cost Pool III

\begin{tabular}{|l|ll|}
\hline Aktivitas & Biaya $(\mathrm{Rp})$ \\
\hline Aktivitas penyusutan: & \multicolumn{2}{|l|}{} \\
\hline Penyusutan gedung (1.093.750.000 x 65\%) & $\mathrm{Rp}$ & 710.937 .500 \\
\hline Total & $\mathrm{Rp}$ & 710.937 .500 \\
\hline
\end{tabular}

Sumber: The Belagri Hotel and Convention Sorong

Tabel 4.10

Cost Pool IV

\begin{tabular}{|l|l|}
\hline Aktivitas & Biaya (Rp) \\
\hline Aktivitas penggajian & \\
\hline Gaji karyawan & \\
\hline$($ Rp245,490,000 $\times 65 \%)+(\mathrm{Rp} 428,520,000 \times 65 \%)+(\mathrm{Rp} 340,155,000 \times 65 \%)+$ & \\
\hline$(\mathrm{Rp} 185,175,000)+(\mathrm{Rp} 273,000,000 \times 65 \%)+(\mathrm{Rp} 489,690 \times 65 \%)+$ & \\
\hline$(\mathrm{Rp} 592,830,000 \times 65 \%)$ & $\mathrm{Rp} 1.660 .659 .000$ \\
\hline Total & \\
\hline
\end{tabular}

Sumber: The Belagri and Convention, 2015

Tabel 4.12

Tarif Cost Pool

\begin{tabular}{|l|rr|r|lr|}
\hline Cost Pool & $\begin{array}{c}\text { Total Cost Pool } \\
\text { (Tabel 4.x) } \\
1\end{array}$ & $\begin{array}{c}\text { Cost Driver } \\
\text { (tabel 4.x) } \\
2\end{array}$ & \multicolumn{2}{|c|}{$\begin{array}{c}\text { Tarif Cost pool } \\
1 \div 2 \\
3\end{array}$} \\
\hline Cost Pool I & $\mathrm{Rp}$ & 6.944 .457 .110 & 17.610 & $\mathrm{Rp}$ & 394.347 \\
\hline Cost Pool II & $\mathrm{Rp}$ & 224.750 .000 & 26.415 & $\mathrm{Rp}$ & 8.508 \\
\hline Cost Pool III & $\mathrm{Rp}$ & 710.937 .500 & 1.956 & $\mathrm{Rp}$ & 363.465 \\
\hline Cost Pool IV & $\mathrm{Rp}$ & 1.660 .659 .000 & 214.656 & $\mathrm{Rp}$ & 7.736 \\
\hline
\end{tabular}

Sumber: The Belagri Hotel and Convention, 2015 
Tabel 4.13

Harga Pokok Produksi Kamar Superior

\begin{tabular}{|c|c|c|c|c|c|c|}
\hline No & Cost Pool & Tar & Cost Poo 1 & $\begin{array}{l}\text { Cost } \\
\text { Driver }\end{array}$ & & Total (Rp) \\
\hline 1 & Cost Pool I & $\mathrm{Rp}$ & 394.347 & 6.800 & $\mathrm{Rp}$ & 2.681 .559 .600 \\
\hline 2 & Cost Pool II & $\mathrm{Rp}$ & 8.508 & 10.200 & $\mathrm{Rp}$ & 86.781 .600 \\
\hline 3 & Cost Pool III & $\mathrm{Rp}$ & 363.465 & 336 & $\mathrm{Rp}$ & 122.124 .240 \\
\hline 4 & Cost Pool IV & $\mathrm{Rp}$ & 7.736 & 71.163 & $\mathrm{Rp}$ & 550.516 .968 \\
\hline \multicolumn{5}{|c|}{ Total biaya tidak langsung } & $\mathrm{Rp}$ & 3.440 .982 .408 \\
\hline \multicolumn{5}{|c|}{ Total biaya langsung } & $\mathrm{Rp}$ & 217.633 .500 \\
\hline \multicolumn{5}{|c|}{ Total biaya untuk kamar superior } & $\mathrm{Rp}$ & 3.658 .615 .908 \\
\hline \multicolumn{5}{|c|}{ Jumlah kamar terjual } & & 6.800 \\
\hline \multicolumn{5}{|c|}{ Harga pokok kamar superior } & $\mathrm{Rp}$ & 538.032 \\
\hline
\end{tabular}

Sumber: The Belagri Hotel and Convention, 2015

Tabel 4.14

Harga Pokok Produksi Kamar Deluxe

\begin{tabular}{|c|c|c|c|c|c|c|}
\hline No & Cost Pool & Tar & Cost Pool & $\begin{array}{l}\text { Cost } \\
\text { Driver }\end{array}$ & & Total (Rp) \\
\hline 1 & Cost Pool I & $\mathrm{Rp}$ & 394.347 & 6.000 & $\mathrm{Rp}$ & 2.366 .082 .000 \\
\hline 2 & Cost Pool II & $\mathrm{Rp}$ & 8.508 & 9.000 & $\mathrm{Rp}$ & 76.572 .000 \\
\hline 3 & Cost Pool III & & 363.465 & 580 & $\mathrm{Rp}$ & 210.809 .700 \\
\hline 4 & Cost Pool IV & $\mathrm{Rp}$ & 7.736 & 62.260 & $\mathrm{Rp}$ & 481.643 .360 \\
\hline \multicolumn{5}{|c|}{ Total biaya tidak langsung } & $\mathrm{Rp}$ & 3.135 .107 .060 \\
\hline \multicolumn{5}{|c|}{ Total biaya langsung } & $\mathrm{Rp}$ & 145.089 .000 \\
\hline \multicolumn{5}{|c|}{ Total biaya untuk kamar deluxe } & $\mathrm{Rp}$ & 3.280 .196 .060 \\
\hline \multicolumn{5}{|c|}{ Jumlah kamar terjual } & & 6.000 \\
\hline \multicolumn{5}{|c|}{ Harga pokok kamar deluxe } & $\mathrm{Rp}$ & 546.699 \\
\hline
\end{tabular}

Sumber: The Belagri Hotel and Convention, 2015

Tabel 4.15

Harga Pokok Produksi Kamar Premier

\begin{tabular}{|r|l|lr|r|rr|}
\hline No & Cost Pool & Tarif Cost Pool & $\begin{array}{c}\text { Cost } \\
\text { Driver }\end{array}$ & \multicolumn{2}{|c|}{ Total (Rp) } \\
\hline 1 & Cost Pool I & $\mathrm{Rp}$ & 394.347 & 4.000 & $\mathrm{Rp}$ & 1.577 .388 .000 \\
\hline 2 & Cost Pool II & $\mathrm{Rp}$ & 8.508 & 6.000 & $\mathrm{Rp}$ & 51.048 .000 \\
\hline 3 & Cost Pool III & $\mathrm{Rp}$ & 363.465 & 600 & $\mathrm{Rp}$ & 218.079 .000 \\
\hline 4 & Cost Pool IV & $\mathrm{Rp}$ & 7.736 & 35.458 & $\mathrm{Rp}$ & 274.303 .088 \\
\hline \multicolumn{5}{|c|}{ Total biaya tidak langsung } & $\mathrm{Rp}$ & 2.120 .818 .088 \\
\hline \multicolumn{5}{|c|}{ Total biaya langsung } & $\mathrm{Rp}$ & 62.871 .900 \\
\hline \multicolumn{5}{|c|}{ Total biaya untuk kamar premier } & $\mathrm{Rp}$ & 2.183 .689 .988 \\
\hline \multicolumn{5}{|c|}{ Jumlah kamar terjual } & & 4.000 \\
\hline \multicolumn{5}{|c|}{ Harga pokok kamar premier } & $\mathrm{Rp}$ & 545.922 \\
\hline
\end{tabular}

Sumber: The Belagri Hotel and Convention, 2015 
Tabel 4.16

Harga Pokok Produksi Kamar Junior Suite

\begin{tabular}{|c|c|c|c|c|c|}
\hline No & Cost Pool & Tarif Cost Pool & $\begin{array}{l}\text { Cost } \\
\text { Driver }\end{array}$ & \multicolumn{2}{|c|}{ Total (Rp) } \\
\hline 1 & Cost Pool I & 394.347 & 500 & $\mathrm{Rp}$ & 197.173 .500 \\
\hline 2 & Cost Pool II & 8.508 & 750 & $\mathrm{Rp}$ & 6.381 .000 \\
\hline 3 & Cost Pool III & 363.465 & 200 & Rp & 72.693 .000 \\
\hline 4 & Cost Pool IV & 7.736 & 20.325 & $\mathrm{Rp}$ & 157.234 .200 \\
\hline \multicolumn{4}{|c|}{ Total biaya tidak langsung } & $\mathbf{R p}$ & 433.481 .700 \\
\hline \multicolumn{4}{|c|}{ Total biaya langsung } & Rp & 19.345 .200 \\
\hline \multicolumn{4}{|c|}{ Total biaya untuk kamar junior suite } & $\mathbf{R p}$ & 452.826 .900 \\
\hline \multicolumn{4}{|c|}{ Jumlah kamar terjual } & \multicolumn{2}{|r|}{500} \\
\hline \multicolumn{4}{|c|}{ Harga pokok kamar junior suite } & $\mathrm{Rp}$ & 905.654 \\
\hline
\end{tabular}

Sumber: The Belagri Hotel and Convention Sorong, 2015

Tabel 4.17

Harga Pokok Produksi Kamar Executive Suite

\begin{tabular}{|c|c|c|c|c|c|c|}
\hline No & Cost Pool & Tar & Tost Pool & $\begin{array}{l}\text { Cost } \\
\text { Driver }\end{array}$ & & otal (Rp) \\
\hline 1 & Cost Pool I & $\mathrm{Rp}$ & 394.347 & 250 & $\mathrm{Rp}$ & 98.586 .750 \\
\hline 2 & Cost Pool II & $\mathrm{Rp}$ & 8.508 & 375 & $\mathrm{Rp}$ & 3.190 .500 \\
\hline 3 & Cost Pool III & $\mathrm{Rp}$ & 363.465 & 180 & $\mathrm{Rp}$ & 65.423 .700 \\
\hline 4 & Cost Pool IV & $\mathrm{Rp}$ & 7.736 & 15.220 & $\mathrm{Rp}$ & 117.741 .920 \\
\hline \multicolumn{5}{|c|}{ Total biaya tidak langsung } & $\mathrm{Rp}$ & 284.942 .870 \\
\hline \multicolumn{5}{|c|}{ Total biaya langsung } & $\mathrm{Rp}$ & 19.345 .200 \\
\hline \multicolumn{5}{|c|}{ Total biaya untuk kamar Executive suite } & $\mathrm{Rp}$ & 304.288 .070 \\
\hline \multicolumn{5}{|c|}{ Jumlah kamar terjual } & & 250 \\
\hline \multicolumn{5}{|c|}{ Harga pokok kamar Executive suite } & $\mathrm{Rp}$ & 1.217 .152 \\
\hline
\end{tabular}

Sumber: The Belagri Hotel and Convention Sorong, 2015

Tabel 4.18

Harga Pokok Produksi Kamar President Suite

\begin{tabular}{|c|c|c|c|c|c|c|}
\hline No & Cost Pool & Tar & ost Pool & $\begin{array}{c}\text { Cost } \\
\text { Driver }\end{array}$ & \multicolumn{2}{|c|}{ Total (Rp) } \\
\hline 1 & Cost Pool I & $\mathrm{Rp}$ & 394.347 & 60 & $\mathrm{Rp}$ & 23.660 .820 \\
\hline 2 & Cost Pool II & $\mathrm{Rp}$ & 8.508 & 75 & $\mathrm{Rp}$ & 638.100 \\
\hline 3 & Cost Pool III & $\mathrm{Rp}$ & 363.465 & 75 & $\mathrm{Rp}$ & 27.259 .875 \\
\hline 4 & Cost Pool IV & $\mathrm{Rp}$ & 7.736 & 10.230 & $\mathrm{Rp}$ & 79.139 .280 \\
\hline \multicolumn{5}{|c|}{ Total biaya tidak langsung } & $\mathrm{Rp}$ & 130.698 .075 \\
\hline \multicolumn{5}{|c|}{ Total biaya langsung } & $\mathrm{Rp}$ & 19.345 .200 \\
\hline \multicolumn{5}{|c|}{ Total biaya untuk kamar president suite } & $\mathrm{Rp}$ & 150.043 .275 \\
\hline \multicolumn{5}{|c|}{ Jumlah kamar terjual } & & 60 \\
\hline \multicolumn{5}{|c|}{ Harga pokok kamar president suite } & $\mathrm{Rp}$ & 2.500 .721 \\
\hline
\end{tabular}

Sumber: The Belagri Hotel and Convention Sorong, 2015 


\subsection{Analisis Metode Activity Based Costing pada The Belagri Hotel and Convention Sorong}

1. Mengidentifikasi aktivitas biaya tidak langsung dan level aktivitasnya.

2. Mengidentifikasi cost driver.

Tabel 4.20

Cost Pool Dan Cost Driver

\begin{tabular}{|l|l|}
\hline Cost Pool & Cost driver \\
\hline Unit level Activity: & \\
Pool I & Jumlah kamar terjual \\
Aktivitas penginapan & Jumlah kamar terjual \\
Aktivitas laundry & Jumlah kamar terjual \\
Aktivitas listrik & Jumlah kamar terjual \\
Aktivitas air & Jumlah kamar terjual \\
Aktivitas telpon & \\
Pool II & \\
Aktivitas pemberian makan pagi & Jumlah tamu menginap \\
Facility Level Activity & \\
\hline Pool I & \\
Aktiivitas penyusutan & Jumlah luas ruangan \\
Aktivitas pemeliharaan & Jumlah luas ruangan \\
Pool IV & \\
Aktivitas penggajian karyawan & Jumlah jam kerja \\
\hline
\end{tabular}

\subsection{Perbandingan Perhitungan Harga Pokok Produksi/Jasa}

Dari hasil perhitungan Harga Pokok Produksi yang digunakan oleh The Belagri Hotel and Convention terlihat adanya perbedaan hasil perhitungan Harga Pokok Produksi Perbedaan tersebut dapat dilihat pada tabel di bawah ini :

\section{Tabel 4.31}

Perbandingan Harga Pokok Produksi

Data Dari Hotel dan Data di Olah dengan sistem Activity Based Costing System

\begin{tabular}{|l|rr|rr|rr|}
\hline Jenis Kamar & $\begin{array}{c}\text { Harga Pokok Produksi } \\
\text { dari hotel } \\
\text { metode ABC system }\end{array}$ & $\begin{array}{l}\text { Harga Pokok Produksi } \\
\text { yang diolah } \\
\text { metode ABC system }\end{array}$ & Selish \\
\hline Superior & $\mathrm{Rp}$ & 538.032 & $\mathrm{Rp}$ & 545.926 & $\mathrm{Rp}$ & $(7.894)$ \\
\hline Deluxe & $\mathrm{Rp}$ & 546.699 & $\mathrm{Rp}$ & 557.072 & $\mathrm{Rp}$ & $(10.373)$ \\
\hline Premier & $\mathrm{Rp}$ & 545.922 & $\mathrm{Rp}$ & 558.598 & $\mathrm{Rp}$ & $(12.676)$ \\
\hline Junior suite & $\mathrm{Rp}$ & 905.654 & $\mathrm{Rp}$ & 938.493 & $\mathrm{Rp}$ & $(32.839)$ \\
\hline Executive suite & $\mathrm{Rp}$ & 1.217 .152 & $\mathrm{Rp}$ & 1.270 .872 & $\mathrm{Rp}$ & $(53.720)$ \\
\hline President suite & $\mathrm{Rp}$ & 2.500 .721 & $\mathrm{Rp}$ & 2.094 .652 & $\mathrm{Rp}$ & $(406.069)$ \\
\hline
\end{tabular}

Dari perhitungan diatas, dapat diketahui bahwa hasil perhitungan Harga Pokok Produksi kamar yang di olah dengan menggunakan metode Activity Based Costing untuk jenis kamar Superior sebesar Rp 545.926, untuk kamar Deluxe sebesar Rp 557.072, untuk kamar Premier sebesar $\mathrm{Rp}$ 558.598, untuk kamar Junior Suite sebesar Rp 938.493, untuk kamar Executive Suite sebesar Rp 1.270.872, untuk kamar President Suite sebesar Rp 2.094.652, Dari hasil yang diperoleh dapat dibandingkan selisih harga pokok produksi kamar yang telah ditentukan manajemen The Belagri and Convention dengan hasil perhitungan menggunakan Activity Based Costing. Untuk metode $\mathrm{ABC}$ yang di olah kembali pada kamar superior, deluxe, premier, junior suite, executive suite, dan president suite memberikan hasil perhitungan yang lebih besar dari pada harga pokok kamar yang telah ditentukan oleh pihak manajemen hotel. Yaitu dengan selisih harga untuk kamar superior sebesar Rp 7.849, untuk kamar deluxe sebesar Rp 10.373, Untuk kamar premier sebesar Rp 12.676, untuk kamar junior suite sebesar Rp 32.839, untuk kamar executive suite sebesar $\mathrm{Rp} 53.720$, dan untuk kamar president suite sebesar Rp 406.069.

Terjadinya selisih harga dikarenakan biaya overhead yang seharusnya di masukkan dalam perhitungan harga pokok produksi, tidak di masukkan hal ini menyebabkan kurangnya mengalokasikan biaya aktivitas ke setiap kamar secara tepat berdasarkan konsumsi masingmasing aktivitas.

\section{Penutup}

\subsection{Kesimpulan}

Berdasarkan hasil penelitian dan pembahasan yang dilakukan oleh penulis dapat ditarik kesimpulan sebagai berikut :

1. Penggunaan metode Activity Based Costing dalam perhitungan harga pokok produksi kamar di Hotel Belagri belum maksimal di karenakan ada beberapa biaya overhead yang menjadi aktivitas dan biayanya yang tidak dimasukkan dalam perhitungannya, seperti aktivitas telpon (biaya telpon), aktivitas penyusutan, (biaya penyusutan peralatan), aktivitas pemeliharaan (biaya pemeliharaan AC), Seragam karyawan.

2. Hasil dari perhitungan harga pokok kamar dengan menggunakan metode Activity Based Costing yaitu, untuk kamar superior sebesar Rp 545.926, Untuk kamar deluxe sebesar Rp 557.027 Untuk kamar premier sebesar Rp 558.598, Untuk kamar junior suite sebesar Rp 938.493 Untuk kamar Executive Suite 
sebesar Rp 1.270.872, dan untuk kamar president suite sebesar Rp 2.094.652, Terdapat selisih harga yang lebih tinggi dari penetapan harga manajemen hotel dengan hasil perhitungan menggunakan metode Activity Based Costing yaitu, untuk kamar superior sebesar Rp 7.894, Untuk kamar deluxe sebesar $\mathrm{Rp} 10.373$, untuk kamar premier sebesar $\mathrm{Rp} 12.676$, untuk kamar junior suite sebesar $\mathrm{Rp} 32.839$, executive suite sebesar Rp 53.720, dan untuk kamar president suite sebesar Rp 406.069

\subsection{Saran}

Dengan menggunakan metode Activity Based Costing System perusahaan dapat mengendalikan biaya lebih baik karena metode Activity Based Costing System merupakan sistem analisis biaya berbasis aktivitas untuk memenuhi kebutuhan manajemen dalam pengambilan keputusan, baik yang bersifat strategis maupun operasional. Maka saran yang dapat diberikan oleh penulis, yaitu :

1. Pihak manajemen hotel sebaiknya mengadakan penelitian lebih lanjut mengenai penerapan Activity Based Costing dalam perhitungan harga pokok produksi kamarnya, sehingga informasi mengenai Harga Pokok Produksi kamar yang lebih akurat dapat diperoleh. Dengan lebih mengidentifikasi biaya overhead yang dapat dijadikan aktivitas dalam menentukan Harga Pokok Produksi kamar.

\section{Daftar Pustaka}

1) A.A. GP. Widanaputra, dkk. 2009 . Akuntansi Perhotelan.Yogyakarta: Graha Ilmu.

2) Al Haryono Jusup. 2011 .Dasar-Dasar Akuntansi. Jilid 2. Yogyakarta: STIE YKPN.

3) Blocher, Edward J. Kung H. Chen, Gary Cokins dan Thomas W. Lin. 2007. Manajemen Biaya Penekanan Strategi. Buku 2. Edisi 3. Jakarta: Selemba Empat.

4) Cecily A. Raiborn dan Michael. 2011. Akuntansi Biaya. Dasar dan Perkembangan. Buku 1. Edisi 7. Terj. Rahmat Hilman. Jakarta: Salemba Empat.

5) Hansen. Don R. Maryanne M. Mowen. 2009. Accounting Manajemen; akuntansi Manajemen. Edisi 8. Jakarta:Salemba Empat Mulyadi. 2007. Activity Based Cost System.
Cetakan 2. Edisi 6. Yogyakarta: UPP STIM YKPN.

6) Mulyadi. 2014. Akuntansi Biaya. Cetakan 12. Edisi 5. Yogyakarta: UPP STIM YKPN. 